\title{
Should dingoes die? Principles for engaging ecocentric ethics in wildlife tourism management.
}

\author{
Georgette Leah Burns $^{\mathrm{a} *}$, Susan Moore ${ }^{\mathrm{b}}$, Jim Macbeth ${ }^{\mathrm{c}}$.
}

${ }^{a}$ Griffith School of Environment and Environmental Futures Centre, Griffith University, Nathan 4111 QLD, Australia

${ }^{b}$ School of Environmental Science, Murdoch University, South Street, Murdoch, 6150

WA, Australia.

${ }^{c}$ School of Social Sciences and Humanities, Murdoch University, South Street, Murdoch, 6150, WA, Australia.

\begin{abstract}
Ethics underlie all our decisions and actions. The aim of this paper is to, first, highlight the sorts of ethical positions that inform wildlife management and, second, to propose a different set of ecocentric ethical principles that not only provide for a more authentic visitor experience of nature but also enhance the long-term survival of wildlife. An ecocentric approach involves locating people in, rather than separate from, nature and so is not possible in locations such as zoos where barriers are physically constructed and maintained between people and wildlife, but should be more compatible with wildlife tourism that is based in rather than on nature. Focusing on wildlife tourism based in nature, seven principles derived from the literature are applied to a case study of dingo management on Fraser Island in Queensland, Australia. The case study demonstrates that recognising the intrinsic value of wildlife and developing a sense of moral obligation and moral reasoning toward the wildlife tourism experience can have positive outcomes for both people and wildlife. If management strategies work within a precautionary principle, acknowledge the interconnectedness between people and nature, and accept that wildlife belongs in nature, then a more ecocentric ethic is possible. This requires managers to engage in a reflexive process with regard to their own ethical position to facilitate the practical application of an ecocentric approach.
\end{abstract}

Keywords: wildlife tourism; ethics; ecocentrism; anthropocentrism; Fraser Island; dingoes

\section{Introduction}

Activities included under the label of wildlife tourism can be very broad and diverse (Newsome, Dowling \& Moore, 2005), and consequently encompass a wide range of ethics. Ethical positions, whether explicit and understood or not, inform wildlife tourism management and an anthropocentric focus is often evident (Dobson, 2006). This paper develops principles to challenge this focus.

Wildlife tourism is frequently defined in the literature as a type or form of tourism that is nature-based (Reynolds \& Braithwaite, 2001), and this remains largely unchallenged. However, the distinction is rarely made between wildlife tourism that

\footnotetext{
*Corresponding author. Email: leah.burns@griffith.edu.au
} 
is based on nature versus wildlife tourism that is based in nature. These two forms may hold different expectations for the tourists and managers, different experiences for the wildlife, and consequently operate more effectively under different management policies and practices. The ethical considerations and implications of each may also be quite different.

This paper argues for the application of an ecocentric ethic to the management of non-consumptive wildlife tourism based in nature. We begin by defining wildlife tourism and distinguishing between tourism based on and in nature. This is followed by a description of some of the existing types of environmental ethics and types of tourists relevant to an exploration of wildlife tourism management. Similarities between wildlife tourists and ecotourists, in particular, are examined because ecocentric values and ethics are likely to be cited as a distinguishing feature of ecotourists (Fennell, 2008). This enables us to argue that attempts in the literature to define tourist types are frequently too essentialist, and anthropocentric ethics guiding wildlife management too restrictive.

We propose a set of seven principles to explain what wildlife tourism management might look like if informed by an ecocentric ethic. These include adopting an intrinsic value for wildlife, creating behaviour change through moral obligations and reasoning, utilising the precautionary principle, recognising the interconnectedness between humans and nature, locating wildlife in nature, and encouraging self-reflexive management. The principles are applied to the current dingo management strategy operating on Fraser Island in Queensland to demonstrate how they can be put into practice.

\section{Part 1: Nature-based wildlife tourism}

This paper is based on the common premise that conceives of nature-based tourism as a form of special interest tourism that establishes a link between tourism and the environment through a diverse range of activities (Valentine, Weiler \& Hall, 1992). We recognise that there is considerable debate on how to define nature itself (Fine 1997), something that is the subject of environmental philosophy (Belshaw, 2001) and thus not a focus here.

Wildlife tourism is frequently defined as a sub-set of nature-based tourism and noted for its close association with ecotourism (Newsome, Dowling \& Moore, 2005; Reynolds \& Braithwaite, 2001). Wildlife tourism can take place on or in nature, and these settings necessitate different ethical considerations.

\section{Wildlife tourism}

'Any living non-human, non-domesticated organism in the kingdom Animalia' (Moulton \& Sanderson, 1999, p. 111) is generally considered to be wildlife, though some definitions also include non-animal species. At its simplest then, wildlife tourism can be defined as any tourist encounters with such wildlife. Wildlife tourism is composed of non-consumptive activities such as viewing, touching and photographing wildlife (Higginbottom, 2004; Fennell, 2008) along with consumptive activities such as fishing and hunting (Lovelock, 2008; Peterson, 2004). The discussion throughout this paper focuses on non-consumptive wildlife tourism, where the death of the wildlife is not the intended outcome of the tourism. Nonconsumption does not mean the use is totally benign (Pitts, 2010). Critiques of the binary opposition of consumptive versus non-consumptive exist in the literature (e.g., Meletis and Campbell 2007) and the distinction is drawn here primarily because the 
management goals and methods can be expected to vary considerably between these two forms.

The overlap of wildlife tourism activities with other forms of tourism, and the wide range of activities included in wildlife tourism (see Horner \& Swarbroke, 2004), makes accurate categorisation problematic (Curtin, 2005); however, wildlife tourism, ideally, is 'about increasing the probability of positive encounters with wildlife for visitors whilst protecting the wildlife resource' (Reynolds \& Braithwaite, 2001, p. 31). It contains all the traditional elements of the tourism system (Baggio, 2008; Mill \& Morrison, 2009), its distinguishing feature being its focus on wildlife as a resource tourists experience (Higginbottom, 2004; Newsome, Dowling \& Moore, 2005; Shackley, 1996). In this light, the relationship between nature-based tourism, ecotourism and wildlife tourism can be represented schematically as shown in Figure 1 .

Figure 1 here

This frequently cited relationship (e.g., Burns 2010; Newsome, Dowling and Moore 2005; Reynolds \& Braithwaite 2001) provides a useful conceptual tool explaining the overlaps between these three types of tourism. Its limits lie in the failure to recognise the complexities of this system. Notably, recognition of the difference between tourism experiences that are on nature versus those that take place in nature is missing.

\section{'On' or 'In' nature?}

Certainly all wildlife is 'nature'; therefore, it could be said that all wildlife tourism is based on an experience with nature. The theoretical placement of wildlife tourism as a subset of nature-based tourism, as shown in Figure 1, is then perfectly logical. However, some wildlife tourism experiences, particularly those involving captive wildlife, take place in settings that are not in nature. The important distinction between tourism based on versus tourism based in nature is rarely addressed in the literature.

Wildlife tourism based on nature involves an experience that focuses on nature, but does not necessarily take place in a natural setting. Visiting a zoo or an urban wildlife park or sanctuary to experience captive wildlife is an example. This type of tourism has a very long history and brings wildlife to a location easily accessible for people. This is primarily done for the benefit and pleasure of people.

In contrast, wildlife tourism based in nature involves an experience based in a natural setting, such as visiting gorillas in a national park in Uganda (Laudati 2010) or wolves in a national park in Canada (Jones 2010). Although this similarly has a long history, its popularity has risen in recent years as access to more remote parts of the world has increased (Higginbottom 2004). Literature integrating discussion of environmental ethics and wildlife tourism has been limited, and has not yet taken into account these crucial locational distinctions.

\section{Environmental ethics}

The different types of ethics are discussed throughout this paper as philosophical positions. These positions underlie the development and maintenance of management policies, techniques and strategies (Acott, La Trobe \& Howard, 1998) in a wide range of contexts: wildlife tourism is no exception. 
The wide variety of ethical positions described in the environmental ethics literature can be conceptualised along a continuum ranging from those that are strongly anthropocentric, placing humans first and foremost at the centre of ethical considerations, to those that are non-anthropocentric, considering humans as part of, but not central to, ethical decision making (Eckersley 1992). These positions range from traditional and intergenerational anthropocentrism at one end, to biocentrism and ecocentrism at the other (Stenmark, 2002). They include, for example, ethical stances based on technocentrism (Pepper 1996), biospheric values (Stern and Dietz 1994) and spirituality (Seligman 1989).

For the purposes of this paper, and the argument for a less anthropocentric approach to the management of wildlife tourism based in nature, the term ecocentrism is adopted to incorporate the range of terms along the continuum that are nonanthropocentric. Aldo Leopold (1949) wrote about the need for humans to recognise their symbiotic relationship with the earth and see themselves as members of the wider biotic community rather than simply the rightful conquerors of it, popularising the term 'ecocentrism'. Critical to the term's usage here is the claim that an ecocentric perspective does not place the rights of humans above those of nonhumans, but instead argues that non-human species have the same rights to live and prosper as humans.

The terms biocentrism and ecocentrism are often used interchangeably. But, a key difference between them is that biocentrism focuses on biological individuals while ecocentrism is a more encompassing term including biological wholes (Stenmark, 2002), such as ecosystems. The organic, or holistic, paradigm guiding an ecocentric approach to environmental ethics sees humans as living in, and being a part of, the wider biophysical environment (Fennell, 2006) or members of a 'biotic community' (Callicott, 2006, p. 128). Ecocentrism encapsulates a 'nature-centred systems of values' (Fennell \& Nowaczek, 2010, p. 242), and both strong and weak versions of ecocentrism have been identified (Stenmark, 2002) - in much the same way as they have been identified in ecotourism. These issues are discussed by Macbeth (2005) but more specifically by tourism and non-tourism scholars such as Collins (1998), Duffy (2002), Holden (2003), Hunter (1997), Merchant (1992), Shrader-Frechette (1981) and Tully (2001).

In zoos, and other captive wildlife settings where the wildlife is removed from its natural habitat, the tourism focus is on, rather than in, nature. The tourism experience is dominantly about positive outcomes for people and is consequently anthropocentric. However, it is also about human appreciation of the individual species rather than the whole ecosystem and appears to fit with a more biocentric ethic of engagement. In contrast, wildlife tourism experiences in nature, where the wildlife is experienced in natural settings, gives tourists the opportunity to better understand the system upon which the wildlife depends and may, therefore, be more ecocentric. The educational potential of tourism that takes place in nature is likely to vary, as will be discussed, from tourism that takes place on nature. Consequently, our focus is on the applicability of an ecocentric position in nature-based wildlife tourism settings. Before discussing this application and the seven principles of an ecocentric approach it is necessary to develop an understanding of the tourists in wildlife tourism settings.

\section{Part 2: Tourists, typologies, and ecocentric management Tourist types}


Who are wildlife tourists? Obviously a wide range of people visit wildlife tourism settings, just as there are a wide range of stakeholders with both shared and differential interests in wildlife tourism enterprises (Burns, 2010). Not all who visit a wildlife tourism setting will classify themselves as wildlife tourists. Newsome, Moore and Dowling (2002, p. 21) narrowly describe wildlife tourists as those who 'seek an experience that will enable them to explore ... a new ecosystem and its inhabitants', and not all definitions are as focused on the in nature context as this one. Just as there are many different kinds of wildlife tourism ventures there are many types of wildlife tourists; and there are tourists who notice wildlife, if not study it. Consequently a wildlife tourist, like wildlife tourism, is difficult to define.

There is a very apparent, and long-standing, preoccupation in the tourism literature with identifying, defining and describing, different types or forms of tourism. This has ranged from attempts to classify tourist types based on potential economic impact in developing countries (e.g., Britton, 1982; Lea, 1988) to identification of types within types for the purpose of specifically targeting those with predetermined beliefs and values (e.g., Cohen, 1974; Zografos \& Allcroft, 2007).

Given the close relationship between wildlife tourism and ecotourism (Figure 1), the assumption can be made that characteristics of ecotourists are shared by some wildlife tourists. For example, ecotourists are more likely to possess an environmental ethic, be more biocentric than anthropocentric oriented, strive for first hand experience, expect an educative and interpretive element to their experience, and aim to benefit wildlife and/or the environment (Balantine \& Eagles, 1994). Eagles and Cascagnette (1995, p. 22) suggest ecotourists 'travel with the intent of observing, experiencing and learning about nature', while Fennell (2006, p. 184) argues 'those who participate (in ecotourism) should be sensitive to the rights of animals as a first priority'.

These positions further emphasise the link between ecotourism and wildlife tourism. However, this discussion also recognises the problems inherent in these definitions. It is not central to the purpose of this paper to review the critique of ecotourism or its sub-fields (e.g., wildlife tourism) but rather to accept that these are common terms useful in this context. The Journal of Ecotourism has published a wide range of articles critiquing the concepts but of particular relevance is the paper by Jamal, Borges and Stronza (2006).

There have been numerous attempts to profile the typical characteristics of ecotourists. Those studying ecotourists have explored their sociodemographics and travel characteristics, and what they seek from a tourism experience (Kerstetter, Hou \& Lin 2004). Kusler (1991), for example, attempts to classify ecotourists on the basis of experience, setting and group dynamics, while Lindberg (1991) identifies four groups based on dedication and time. Mehmetoglu (2007) develops a tourist typology based on trip activities. Weaver (2001) differentiates between 'hard' and 'soft' ecotourists, and offers a model of 'comprehensive' versus 'minimalist' ideal types (in Weaver, 2005). Dichotomies such as these, and others such a 'deep' and 'shallow' ecotourists (Acott, La Trobe \& Howard, 1998), are common in the literature.

This breadth reminds us that ecotourists are difficult to define because their motivations often overlap with other types of tourists (Wight, 1996), and this similarly applies to wildlife tourists. The models posed by these, and other, authors are useful conceptual tools to help us think about tourist types; however, there is a need to be aware of the false homogeneity they can portray and acknowledge the intragroup differences that may exist (Fennell, 2007). Using the labels can create a false 
differentiation and may also exclude other tourists who are more 'casual' participants in and observers of nature. The next section expands on some of these issues.

\section{Which tourists to target?}

The question arises, then, in arguing for an ecocentric approach to managing wildlife tourism, of which tourists to target. An ecocentric approach to wildlife tourism might work better, in terms of enhanced positive outcomes for both the people and the wildlife with, for example, those Weaver (2005) classifies as 'comprehensive' ecotourists, or those engaging in the type of 'deep' ecotourism described by Acott, La Trobe and Howard (1998). 'Hard' ecotourism, characterised by small groups of travellers who are usually more environmentally aware and seek challenging experiences in less-serviced nature-based settings, may fit better with ecocentric wildlife tourism than 'soft' ecotourism which involves larger numbers in serviced sites having a more superficial experience of nature (Fennell \& Weaver, 2005, p. 378). Using these categories, 'hard', 'comprehensive' or 'deep' wildlife tourists may equate more often with those seeking an experience in nature-based settings and 'soft', 'minimalist' or 'shallow' wildlife tourists with those who base their experience on, but not in, nature.

There is a practical limit, however, to the consequences of determining the 'right' type for this kind of approach. Policies and strategies guiding the management of a wildlife tourism destination might recognise different types of visitor use, separating fishers from birdwatchers for example, but are restricted in their ability to put different strategies in place for the multiple possible different types of tourists.

A further problem with these classifications is that different types of tourists may visit the same destinations. Also, as Acott, La Trobe and Howard (1998) describe, different people might do different things at different locations for different reasons. The reality is that the management has to accommodate all of them. Therefore, we argue it is prudent to focus on management policies and strategies rather than which tourists to target. In the face of limited information and given that different types of tourists may visit the same destination, it is best to focus on managing the setting rather than the people to provide a diversity of opportunities and experiences (McCool, Clark \& Stankey, 2007).

More than 60 years ago Leopold (1949) recognised that a change in ethics with regards to human interactions with the natural world would not come about easily, but was optimistic that progress was being made. It would need to be accompanied, though, by an internal change in matters related to our intellectual emphasis, loyalties, affections and convictions. Hardin (1968) similarly suggested the need for a moral shift in human behaviour. Although many people may have made these shifts, it is almost certainly the case that not everyone will. There is no evidence in human history to suggest that such a level of homogeneity is possible, and so we need to work around it; hence our argument to take the imperative for change beyond individuals and into management.

Research by Kortenkamp and Moore (2001) identified the importance of both individual differences and situational variables in the expression of environmental ethical reasoning, suggesting that it is not necessary to solely target individuals. Our argument is that management strategies should change to reflect an ecocentric ethic, recognising that this may work more effectively with some tourist types than others, but should be applied to all. Managers should use these ethical positions to generate operative reasons for management policies, but before they can do this they need some principles to guide an ecocentric approach to management. 


\section{What does an ecocentric approach look like?}

Applying an ecocentric approach to management policies, decisions and strategies would require an ontological perspective that differs from the usually dominant anthropocentric worldview. An ecocentric worldview sees the world as 'an intrinsically dynamic, interconnected web of relations in which there are no dividing lines between ... the human and the non-human' (Eckersley, 1992, p. 49). The practice in wildlife tourism is frequently to apply the metaphysical through the creation of physical divisions, in the form of fences for example, between the tourists and the wildlife. Anthropocentrism is the ontological position behind the humannature dualism, in which separation is necessary to support the socially constructed hierarchy that places humans as morally superior to nonhumans (Purser, Park \& Montuori, 1995). The anthropocentric assumption guiding much wildlife tourism management is that humans are above nature, and both nature (Purser, Park \& Montuori, 1995) and the non-human animals in it (Hughes, 2001) are viewed as objects to be managed. Construction as objects rather than subjects validates human treatment of animals for instrumental purposes (Franklin, 2008; Jamal, Borges and Stonza 2006) rather than affording them any intrinsic value. To move beyond this we considered what an ecocentric informed wildlife tourism management would look like and devised the following seven interlinked principles (Table 1). These principles were developed from the literature on ecotourism, wildlife tourism and environmental ethics, and from the collective experience and expertise of the authors.

Table 1 here

An ecocentric approach calls for recognition of the intrinsic value of the wildlife and the wildlife habitat, whether tourism destination (Acott, La Trobe \& Howard, 1998) or in the face of any other human uses (development). Principle 1, the Intrinsic Value Principle, notes that wildlife has value in and of itself, and that this value is independent of the wildlife's usefulness to human activities. It also recognises that spiritual values are important in and of themselves, paving the way for incorporating alternate ethical positions such as those found in Indigenous communities (Kelbessa, 2005; Morito, 2000; Yasol-Naval, 2002). This principle reflects the holistic prerogative of ecotourism that sees moral concern based primarily on features of natural systems rather than individuals (Hettinger \& Throop, 1999).

The Moral Obligations Principle, Principle 2, advocates creating behaviour change through moral obligations. Enabling visitors to become aware of the environmental consequences of their actions can compel them to change their behaviour through a sense of moral obligation (Bamberg \& Moser, 2007; De Groot \& Steg, 2007). Promoting this awareness of consequences, to not just the individual wildlife but also the ecosystem that supports them, should be part of the wildlife tourism management approach. This draws on norm-activation theory (Schwartz, 1977), which proposes that 'awareness of consequences of environmental damage will compel a person who believes his or her actions can ameliorate those consequences to feel a sense of moral obligation to act' (Kortenkamp \& Moore, 2001, p. 3). In the context of wildlife tourism, this theory supports the idea that a management plan that empowers visitors to the location to be aware of, and responsible for, their own actions may have positive outcomes for both the people and the wildlife. 
This is connected directly with Principle 3, the Moral Reasoning Principle, which focuses on developing moral reasoning. Providing information on environmental ethics facilitates visitors in undertaking ecocentric moral reasoning. The approach should include information about environmental ethics because studies (e.g., Kortenkamp \& Moore, 2001) have shown this elicits more ecocentric moral reasoning. Put simply, it is more difficult to consider the interests of the wildlife and their habitat if those interests are not known. Consequently, ecocentric management strategies should offer information about the wildlife, its habitat, and the potential effects on these by human actions; understanding ecosystem principles is also important here.

Consumptive use of wildlife, for human activities of hunting and fishing, may be the more 'traditional' concerns of wildlife management agencies (Pitts, 2010, p. 1) than non-consumptive tourism activities such as viewing and photographing wildlife. Moving toward a less anthropocentric, and more ecocentric, position would require embracing the idea that the overarching goal of wildlife management should be to protect wildlife rather than ensure a maximum sustainable harvest rate (Regan, 1983). That said, other environmental factors may suggest that certain consumptive activities are necessary from an ecocentric perspective, due, for example, to factors such as lack of natural predators and human induced limited habitat.

The notion of human protection of nature is itself, of course, a particular type of construct and open to debate. The desire to protect can be seen as a reflection of anthropocentric interests and part of the politics of power over nature. In the JudeoChristian ethic, for example, protection exists from the point of human domination over non-humans and over nature (Macbeth, 2005) although recent interpretations allocate a stewardship role to humans. There can be little argument, however, that protection is less anthropocentric than consumption and there is no denying the power differentials that themselves require humans to embrace 'protection' strategies.

Although the idea of prioritising protection over consumption is not new, the legacy of this focus is often still apparent in wildlife tourism settings based in nature. In many cases however, where non-consumptive tourism activities take precedent over consumptive ones, the focus shifts from maximising the harvest rate the wildlife as a resource can support to maximising the economic profit gained from tourism. Prioritising wildlife protection can be difficult to enact in tourism settings where an obvious anthropocentric goal is profit for humans, and thus potential conflict exists. Consequently, there is a need for recognition in management that adequate assessment of the impact of a wildlife tourism venture must go beyond conventional economic accounting (Acott, La Trobe \& Howard, 1998). Such recognition requires the wildlife to be seen as more than just a resource to exploit, either consumptively or nonconsumptively. It also requires tourists to be seen as having moral obligations in the wildlife tourism setting.

The Precautionary Principle (4) is an important aspect of environmental ethics and should be implemented as a vital component of policy formation (Acott, La Trobe \& Howard, 1998). To date it appears largely absent from wildlife tourism management considerations. This fourth principle concerns precautionary action and the burden of proof. It essentially argues that if a wildlife tourism action has a suspected risk of causing harm to animals or their habitat, in the absence of scientific consensus that the action is harmful, then the burden of proof that it is not harmful falls on those proposing the action.

Principle 5, the Avatar Principle, stresses the interconnectedness of humans and nature. Seen as inseparable, both people and wildlife require management as part of 
shared ecosystems. An ecocentric perspective is not misanthropic (Purser, Park \& Montuori, 1995). In moving away from anthropocentrism as a guiding ethical position we are not arguing a case for elevating wildlife to a moral level above humans. Instead we are challenging management to conceptualise people as part of nature; as a component in the wildlife tourism setting (Burns, 2009). This also has resonance with eastern philosophies such as Hinduism and Buddhism (Paterson, 2006).

Principle 6, the Belonging in Nature Principle, emphasises that wildlife belong in nature. An imperative is visitors acknowledging that animals belong in and with nature, and that people are the visitors in the wildlife tourism setting. If visitors are aware that the wildlife and its habitat is an integral part of the in nature-based setting then they may be more likely to accept the conditions of that setting and the behaviour of that wildlife without seeking to change it (Burns, 2009). This change in perspective, that is, not seeing humans as the 'owner', implicitly supports and is congruent with an ecocentric ethic.

The success of all previous six principles is compromised unless managers can acknowledge their own ethical positions. Principle 7, the Reflective Manager Principle, encourages managers to reflect on how their ethical position is constructed and could potentially change over time through interactions with others (including animals). This follows Macbeth's (2005, p. 963) argument that managers 'should engage with and understand the ethics of their positions; an ethically reflexive' process is required in developing management strategies. Understanding contrasting and complementary ethical issues will allow for better management decisions, and such self-awareness and understanding is vital to enable managers to be able to comprehend, and ultimately embrace, alternative ethical positions.

Our intention is to apply this set of seven principles to an example of an existing management strategy in a location that is a destination for wildlife tourism, amongst many other types of tourism. We are using these principles because an objective is to provide guidelines for management strategies that are fair to species other than humans, to ensure that humans in their treatment of other species do not violate the rights of all to flourish (Stenmark, 2002). We are seeking change that will foster a deeper appreciation of the intrinsic valuation of nature. In this way it is a move toward a more 'ecocentric responsibility paradigm' and away from 'anthropocentric environmental management’ (Purser, Park \& Montuori, 1995, p. 1069).

\section{Part 3: Informing the Fraser Island Dingo Management Strategy (FIDMS)}

The preceding sections have laid the basis for us to apply the seven principles of ecocentric management to a specific case of wildlife tourism: dingo management on Fraser Island. This analysis will suggest a management approach that is congruent with the principles enunciated above.

Located off the coast of north-eastern Australia, Fraser Island is the world's largest sand island. Its popularity as a tourist destination stems from its unique flora and fauna, recognised through World Heritage listing, and dingoes are part of this broad tourism experience for island visitors. The wild dingo population on the island is managed by the Queensland Parks and Wildlife Service, in accordance with the Fraser Island Dingo Management Strategy (FIDMS).

The FIDMS is not specifically a tourism management document, yet many of the 91 actions that form part of the 7 strategies (Table 2) within it are focused on managing interactions between dingoes and people in a nature-based setting. In the case of Fraser Island, which is home for approximately 200 residents and receives in 
excess of 350,000 visitors each year, the majority of the people targeted are tourists. Consequently, the FIDMS informs management of tourism even though that may not be its explicit aim.

A draft Fraser Island Dingo Management Strategy (Environmental Protection Agency [EPA], 1999) existed for several years prior to a first dingo-caused human fatality on the island in April 2001. This prompted the swift undertaking of a risk management assessment in May 2001 (EPA, 2001a) after which the finalised FIDMS was released in November that year (EPA, 2001b). The FIDMS was audited in 2003 (Corbett, 2003), reviewed in 2006 (EPA, 2006), and audited again in 2009 (Corbett, 2009). The intense attention to this document reveals the importance and complexities of managing this wildlife species in a location with heavy visitation.

Table 2 here

The human fatality triggered an increased anthropocentric approach to managing dingoes on the island, justified by the Environmental Protection Agency (EPA) because the fatality 'dramatically redefined the risk that Dingoes pose to humans' by proving 'that the most severe outcome, namely a human death, is possible' (2001b, p.x). Thirty-one dingoes were immediately killed following the human fatality and dingoes continue to be 'destroyed' as part of their ongoing management on the Island (Corbett, 2009). Dingo deaths are deemed acceptable under an approach that regards a human death as 'the most severe outcome' and thus obviously an outcome to be prevented regardless of the cost to non-human lives. Justification based on insurance liability risk has never been explicitly raised even though it underpins many of the management choices made. The recent audit by Corbett (2009), a wildlife ecologist, does nothing to challenge the anthropocentric position dominant in the current FIDMS. This underlying ethic is clear in the FIDMS.

\section{Current anthropocentric focus of the FIDMS}

The current anthropocentric focus of the FIDMS is evident in its 7 key strategies (see Table 2 above) and the 91 actions underpinning them. An assumption underlying many of the strategies in the FIDMS is the expectation that dingoes should not frequent human areas. This ideological separation locates dingoes as part of the natural landscape but humans, and the areas they occupy and use, as part of a separate (and superior) cultural landscape (Hytten \& Burns, 2007). Interactions between humans and dingoes are constructed as always negative (Burns, 2006). The FIDMS (EPA, 2001b, p. 10; Corbett, 2009, p. 22) manages human-dingo interactions 'by increasing Island-wide facilities and services that discourage dingoes from interacting with the people', as detailed in Strategy 3. These facilities and services take the form of both physical and metaphysical barriers that enforce the separation of humans and dingoes. Their main function is to avoid harm to people.

Within the seven strategies, five types of action are particularly relevant to this paper. Three of these, fencing, hazing and culling (killing), target dingo behaviour and two, fines and education, target humans. They all do so with an anthropocentric focus.

The recent FIDMS audit applauds the use of fencing on the island, stating that 'fences, at about 15 sites to date, have been very successful in minimising dingohuman interactions' (Corbett, 2009, p. 24). The fencing, which started in 2006, creates physical boundaries around many campgrounds, day use areas, and some resorts and townships (Burns \& Howard, 2003; Burns, 2010). The audit recommends fencing on 
the island be expanded to include 'public dumps' and 'public areas' (Corbett, 2009, p. 23).

The FIDMS also outlines the implementation of programs designed to modify dingo behaviour (Corbett, 2009). Strategy 4 encompasses different types of hazing techniques (such as ultrasonic devices, rat shot guns and sling shots) and aversive baiting. The modification sought is a change in dingo behaviour to make it match human expectations of the island as a safe destination (Hytten \& Burns, 2007).

Justification to kill dingoes occurs in two of the seven strategies, although the question of whether dingoes should die is never addressed. Strategy 5 advocates the destruction of dingoes deemed by QPWS staff to be 'dangerous', and Strategy 6 proposes a need to cull dingoes to maintain a sustainable population on the island (for 'sustainable' read smaller). There is a very big problem with this. Size of the current dingo population is unknown. Consequently it is not possible to determine what is a sustainable level, or even whether the population can survive the current destruction practices (Corbett, 2009). The EPA (2001b; 2006) states that an important objective of the culling is to balance dingo numbers with availability of nature foods. Instead, the resultant imbalance favours human use of the spaces on the island over dingo use (Hytten \& Burns, 2007). Culling is the ultimate demonstration of 'conservation as control' (Adams, 2003b, p. 235), and clearly anthropocentrically driven. The message implicit on the FIDMS is that individual dingoes must die, to keep humans safe and for the benefit of the dingo population as a whole.

Fines are used as one of two main ways to modify human behaviour on Fraser Island, again with the motive of separating humans and dingoes so the two do not interact. Fines for interacting with dingoes, either directly through hand feeding or indirectly through leaving food where dingoes could access it, were increased significantly following the fatality.

Education is the second way human behaviour is targeted. Public education is a large component of Strategy 2, which seeks to 'encourage appropriate behaviour towards dingoes by Island visitors, residents and staff' (Corbett, 2009, p. 6). This includes educational messages, personal contact and public awareness and surveys. The appropriate behaviour is deemed to be that which keeps humans and dingoes apart.

The FIDMS offers no suggestions about managing the wider habitat in which the dingoes reside, and is therefore biocentric as well as anthropocentric. Analysis of it suggests that management on Fraser Island is consistent with dominant western discourses that overwhelmingly prioritise people whilst simultaneously marginalising wildlife (Burns, 2009; Hytten \& Burns, 2007).

\section{Applying ecocentric principles to current strategies for managing dingoes on Fraser Island.}

The FIDMS strategies correlate strongly with an anthropocentric approach. In contrast, an ecocentric approach, as embodied in our principles, removes the need for separation and refocuses the aims of management.

Shifting the perception of the value of dingoes from instrumental to intrinsic, in accordance with Principle 1, enables both managers and tourists to step away from a preoccupation with what dingoes can offer for people and allows this form of wildlife to be viewed as valuable simply because it exists within the Fraser Island location. The principle recommends that the treatment of both the dingoes and their supporting habitat as intrinsically valuable be made explicit in management policy, such as the FIDMS. This value can be conveyed in educational messages to tourists visiting the 
Island, offering an alternate discourse to the instrumental one that exists currently. This ideological shift towards intrinsic value recognition has implications for acting out the other six principles.

Adopting Principle 2 facilitates a change to human expectations of the destination, rather than harming dingoes, by encouraging a moral obligation to wildlife. Human visitors alter their expectations of the wildlife tourism destination, recognise their moral obligations to the wildlife and the habitat, and assume new responsibilities. This principle advocates informing visitors to the site of the consequences of their actions. Visitors to Fraser Island need to be aware of the potentially fatal consequences for the dingoes of interactions. The widespread public response to the cull in May 2001 was largely unsupportive of the killing of dingoes (Burns \& Howard, 2003), indicating a potential for acceptance of less anthropocentric management.

There is also scope to develop moral reasoning (Principle 3) within the management of this wildlife tourism destination. For example, the results from a study by Thompson and Barton (1994, p.156) of attitudes toward the environment suggested that 'programs that attempt to foster interest in supporting environmental action for utilitarian, human comfort, and survival reasons may be counterproductive'. They argue instead 'a better approach might be to emphasise the intrinsic rewards of being in natural settings through an experience in nature and the appreciation of wildlife’ (p156). To assist the development of moral reasoning on Fraser Island, educational material for visitors could include information about environmental ethics and provide information about the dingoes and their habitat.

Implementing the Precautionary Principle (4) is especially crucial on Fraser Island. As described earlier, there are serious knowledge gaps about the location's dingoes, including crucial data on exact population numbers. If dingo numbers are low, managing behaviour by killing individuals could have detrimental outcomes for the population as a whole. In the face of these unknowns, the precautionary principle has great value. The onus is on managers to prove that the action of continued killing is justifiable.

The FIDMS focuses on the negative effect that interactions between dingoes and visitors could have for people. The underlying assumption is that all interactions are negative and thus all interactions should be avoided. Currently, feeding and interacting with dingoes is blamed for their habituation that is in turn blamed for dangerous behaviour toward people. The outcome then is that the people could get hurt or the dingoes could get shot. Where the latter outcome is sold as a potential loss, it is described as a loss for humans because it decreases their opportunity to see dingoes on the island. Here the Avatar Principle (5), that all life is interconnected, is useful. Rather than assuming all interactions are negative and thus people and dingoes need to be separated, the FIDMS could acknowledge that not all interactions are negative and manage for both in a more interconnected and holistic framework.

The FIDMS could be more holistic. An ecocentric position would acknowledge people in nature and recognise the ecosystem that supports the dingoes and other Fraser Island wildlife, and ultimately then supports wildlife tourism. This fits with Principles 5 and 6. Examples of this more holistic approach exist in other tourism contexts based in nature. In the Bouma Forest Park on the Fijian island of Taveuni, interpretive signage for tourists informs them to 'Beware the birds of Tavoro. They own this land' and 'Do not disturb the plants of Tavoro. This is their land'. A further example can be found in some Canadian National Parks, where the recognition of human responsibility in nature-based wildlife tourism settings has already occurred. 
Parks Canada, for example, produces a brochure for visitors which opens with the statement:

You are in Black Bear Country. ... As a national park visitor, you share this natural area with bears and other wildlife that depend on it for their survival. ... By increasing your knowledge of bear behaviour, you can reduce the likelihood of an unpleasant encounter, and at the same time, help protect the black bear population. With your cooperation, bears and people can co-exist (Parks Canada, 2008).

Managers on Fraser Island could adopt a similar approach in the messages they convey to visitors about dingoes. In accordance with the belonging in nature principle (6), the Island would not be marketed solely as a safe, human dominated, location. Instead, the intrinsic value and place of dingoes within the ecosystem would be emphasised. Informed that dingoes belong in the ecosystem that the people are visiting, and that dingoes may be aggressive, leaves visitors with the choice of whether to venture to this tourist destination (Burns, 2009).

The FIDMS is essentially anthropocentric. Future management decisions on the Island could benefit from acknowledging this, and from encouraging managers to be reflexive about their ethical positions. Increased understanding about how ethical positions are constructed and alter over time can assist to facilitate change. Adopting the seven principles outlined above has potential to work, and to decrease the need for separating people and dingoes.

\section{Conclusion}

Wildlife tourism, as a subset of nature-based tourism and in its overlaps with ecotourism, seems to have potential to accept a change in management strategies from an anthropocentric to an ecocentric ethic. However, wildlife tourism ventures that occur in nature have different ethical considerations to those that are based on nature but do not occur within it. Consequently, the management of tourism in these two settings will have different requirements and this needs to be acknowledged.

We have suggested here that some wildlife tourists, especially those we aligned with established definitions of 'comprehensive', 'hard' or 'deep' ecotourists, travel with the intent of both experiencing and learning about wildlife, and are potentially more open to ecocentric aims. The benefit of this is that 'Those who are more ecocentric are more likely to act on their pro-environment attitudes and engage in conserving behaviours' (Thompson \& Barton, 1994, p. 156). These would appear to be the types of tourists to target for the ecocentric management approach we are advocating.

It is not practical, however, from a management perspective to simply target a single group in each wildlife tourism destination, even if they could be identified. And, as we acknowledged, types of tourists are difficult to define and labels can create a false sense of homogeneity, or differentiation, both within and between groups. Consequently, we devised seven principles for managing all visitors to a wildlife tourism destination based in nature rather than focus on a particular type of tourist or segment of the tourism community.

In order to enhance authentic wildlife experiences and to protect the intrinsic nature of wildlife, management strategies need to stop reinforcing an anthropocentric ethic, by recognising an ecocentric ethic. This is not simple to bring about. Documents expressing policies of anthropocentrism are much easier to find than those expressing non-anthropocentrism (Stenmark, 2002) - clearly a legacy of our western philosophical engagement with nature that has celebrated a conquering and separating 
mentality (Adams, 2003b; Burns, 2010; Plumwood, 2003; Suchet, 1999). This legacy needs to be challenged, especially in our interactions with wildlife. A key example of this barrier can be found in the often quoted directive for sustainable development from the World Commission on Environment and Development (WCED) (1987) which focuses on meeting the needs of the present and future generations (of humans). Here intergenerational anthropocentrism is clearly the guiding principle behind the call for conserving resources, and more ecocentric ideas take a back seat (Stenmark, 2002).

Similarly, the prevalence of anthropocentrism in wildlife tourism is a problem. Traditional definitions, such as the one presented earlier by Reynolds and Braithwaite (2001), which focus on positives for people and protection for wildlife, are blatantly anthropocentric.

An ecocentric approach to managing wildlife tourism proposes a new way of engaging humans and non-human animals in nature-based settings. The Intrinsic Value principle allows us to question the way we value wildlife and why we value in this way, proposing an engagement that focuses on an intrinsic rather than instrumental value. This paves the way for creating behaviour change in visitors to wildlife tourism destinations through encouraging them to become aware of their Moral Obligations to the wildlife and the destination. Similarly, providing information on environmental ethics assists visitors towards Moral Reasoning about the wildlife, the habitat, and their tourist experience. Encouraging tourists to be aware of their responsibility, for themselves and to nature, may be a positive step forward in wildlife settings (Burns, 2009).

The Precautionary Principle is well established in literature about nature and the environment, but has yet to be implemented widely in wildlife tourism management considerations. In the Australian context at least, most management policies and practices do not focus on interconnectedness between humans and nature. Redressing this, through the Avatar Principle, removes the need for separation that is a driving force in many management strategies. If tourists are aware that wildlife and other forms of nature are an integral part of the setting, then they are more likely to be accepting of their behaviours (Burns, 2009), and this is the basis of the Belonging In Nature Principle. Finally, a Reflexive Manager Principle is necessary to encourage managers to think critically about their own ideologies and ethical constructions.

Combining these seven principles provides guidelines for managers to approach and guide wildlife tourism experiences in a more ecocentric way. It provides for more authentic visitor experiences of nature and enhances the long-term survival of wildlife. It also enables us to question whether dingoes should die as a consequence of interactions with humans.

\section{References}

Acott, T.G., La Trobe, H.L. and Howard, S.H. (1998). An evaluation of deep ecotourism and shallow ecotourism. Journal of Sustainable Tourism, 6(3), 238253.

Adams, W.M. (2003a). When nature won't stay still: Conservation, equilibrium and control. In W.M. Adams and M. Mulligan (Eds.), Decolonizing nature: Strategies for conservation in a post-colonial era (pp. 220-246). London: Earthscan.

Adams, W.M. (2003b). Nature and the colonial mind. In W.M. Adams and M. Mulligan (Eds.), Decolonizing nature: Strategies for conservation in a postcolonial era (pp. 16-50). London: Earthscan. 
Balantine, J. and Eagles, P.J. (1994). Defining the Canadian ecotourist. Journal of Sustainable Tourism, 2(4), 210-214.

Baggio, R. (2008). Symptoms of complexity in a tourism system. Tourism Analysis, 13(1), 1-20.

Bamberg, S. and Moser, G. (2007). Twenty years after Hines, Hungerford, and Tomera: A new meta-analysis of psycho-social determinants of proenvironmental behaviour. Journal of Environmental Psychology, 27, 14-25.

Belshaw, C. (2001). Environmental Philosophy. Chesham, UK: Acumen.

Britton, S. (1982). The political economy of tourism in the third world. Annals of Tourism Research, 9(3), 331-358.

Burns, G.L. (2006). The fascination of fur and feathers: managing human-animal interactions in wildlife tourism settings. Australian Zoologist, 33(4), 446-457.

Burns, G.L. (2009). Managing wildlife for people or people for wildlife? A case study of dingoes and tourism on Fraser Island, Queensland, Australia. In J. Hill and T. Gale (Eds.), Ecotourism and environmental sustainability: Principles and practice (pp.139-155). Surry: Ashgate.

Burns, G.L. (2010). Dingoes, penguins and people: Engaging anthropology to reconstruct the management of wildlife tourism interactions. Saarbrucken: Lambert Academic Publishing.

Burns, G.L. and Howard, P. (2003). When wildlife tourism goes wrong: A case study of stakeholder issues regarding Dingoes on Fraser Island, Australia. Tourism Management, 24, 699-712.

Cohen, E. (1974). Who is a tourist? A conceptual clarification. Sociological Review, 22(4), 527-555.

Collins, A. (1998). Tourism development and natural capital. Annals of Tourism Research, 25, 98-109.

Corbett, L. (2003). Audit of the Fraser Island dingo management strategy. Report to Queensland Parks and Wildlife Service by ERA Environmental Services Pty Ltd.

Corbett, L. (2009). Audit (2009) of Fraser Island dingo management strategy. Brisbane: Queensland Parks and Wildlife Service.

Curtin, S. (2005). Nature, wild animals and tourism: An experiential view. Journal of Ecotourism, 4(1), 1-15.

De Groot, J. and Steg, L. (2007). Value orientations and environmental beliefs in five countries: Validity of an instrument to measure egoistic, altruistic and biospheric value orientations. Journal of Cross-Cultural Psychology, 38(3), 318-323.

De Groot, J. and Steg, L. (2009). Morality and prosocial behaviour: The role of awareness, responsibility, and norms in the norm activation model. The Journal of Social Psychology, 149(4), 425-449.

Dobson, P. (2006). Sharks, wildlife tourism and state regulation. Tourism in Marine Environments, 3(1), 15-23.

Duffy, R. (2002). A Trip Too Far: Ecotourism Politics and Exploitation. London: Earthscan Publications.

Eagles, P.F. and Cascagnette, J.W. (1995). Canadian ecotourists: Who are they? Tourism Recreation Research, 20(1), 22-28.

Eckersley, R. (1992). Environmentalism and Political Theory: Towards an Ecocentric Approach. London: UCL Press.

EPA (Environmental Protection Agency) (1999). Draft Fraser Island dingo management strategy. Brisbane: Queensland Parks and Wildlife Service. 
EPA (Environmental Protection Agency) (2001a). Risk assessment - Risk to humans posed by the dingo population on Fraser Island. Brisbane: Queensland Parks and Wildlife Service.

EPA (Environmental Protection Agency) (2001b). Fraser Island dingo management strategy. Brisbane: Queensland Parks and Wildlife Service.

EPA (Environmental Protection Agency) (2006). Fraser Island Dingo management strategy - review. Brisbane: Queensland Parks and Wildlife Service.

Fennell, D. (2006). Tourism Ethics. Clevedon: Channel View Publications.

Fennell, D. (2007). Ecotourism ( $3^{\text {rd }}$ Ed.). London: Routledge.

Fennell, D. (2008). Ecotourism and the myth of indigenous stewardship. Journal of Sustainable Tourism, 16(2), 129-149.

Fennell, D. and Nowaczek, A. (2010). Moral and empirical dimensions of humananimal interactions in ecotourism: Deepening an otherwise shallow pool of debate. Journal of Ecotourism, 9(3), 239-255.

Fennell, D. and Weaver, D. (2005). The ecotourism concept and tourismconservation symbiosis. Journal of Sustainable Tourism, 13(4), 373-390.

Fine, G. (1997). Naturework and the taming of the wild: The problem of "overpick" in the culture of mushroomers. Social Problems, 44(1), 68-88.

Franklin, A. (2008). The 'animal question' and the 'consumption' of wildlife. In B. Lovelock (Ed.), Tourism and the consumption of wildlife (pp. 31-44). London: Routledge.

Hardin, G. (1968). The tragedy of the commons. Science, 162, 1243-8.

Hettinger, N. and Throop, B. (1999). Refocusing Ecocentrism: De-emphasizing Stability and Defending Wildness. Environmental Ethics, 21, 3-21.

Higginbottom, K. (2004). Wildlife tourism: An introduction. In K. Higginbottom (Ed.), Wildlife tourism: Impacts, management and planning (pp. 1-14). Alton, Victoria: Common Ground Publishing.

Holden, A. (2003). In Need of New Environmental Ethics for Tourism? Annals of Tourism Research, 30, 94-108.

Horner, S. and Swarbroke, J. (2004). International Cases in Tourism Management. London: Elsevier.

Hughes, P. (2001). Animals, values and tourism - structural shifts in UK dolphin tourism provision. Tourism Management, 22(4), 321-329.

Hunter, C. (1997). Sustainable Tourism as an Adaptive Paradigm. Annals of Tourism Research, 24, 850-867.

Hytten, K. and Burns, G.L. (2007). Deconstructing dingo management on Fraser Island: The significance of social constructionism for effective wildlife management. Australasian Journal of Environmental Management, 14, 48-57.

Jamal, T. Borges, M. and Stronza, A. (2006). The institutionalisation of ecotourism: Certification, Cultural Equity and Praxis. Journal of Ecotourism, 5(3), 145-175.

Jones, K. (2010). From big bad wolf to ecological hero: Canis Lupus and the culture(s) of nature in the American-Canadian West. American Review of Canadian Studies, 40(3), 338-350.

Kelbessa, W. (2005). The rehabilitation of Indigenous environmental ethics in Africa. Diogenes, 207, 17-34.

Kerstetter, D., Hou, J-S. and Lin, C-H. (2004). Profiling Taiwanese ecotourists using a behavioural approach. Tourism Management, 25, 491-498.

Kortenkamp, K. and Moore, C. (2001). Ecocentrism and anthropocentrism: Moral reasoning about ecological commons dilemmas. Journal of Environmental Psychology, 21, 261-272 
Kusler, J.A. (1991). Ecotourism and resource conservation: Introduction to issues. In J.A. Kusler (Ed.), Ecotourism and resource conservation: A collection of papers. Volume 1. Madison WI: Omnipress.

Laudati, A. (2010). Ecotourism: the modern predator? Implications of gorilla tourism on local livelihoods in Bwindi Impenetrable National Park, Uganda. Environment and Planning D: Society and Space, 28, 726-743.

Lea, J. (1988). Tourism and Development in the Third World. London: Routledge. Leopold, A. (1949). A Sand County Almanac. New York: Oxford University Press.

Lindberg, K. (1991). Policies for Maximising Nature Tourism's Ecological and Economic Benefits. Washington, D.C.: World Resources Institute.

Lovelock, B. (Ed). (2008). Tourism and the consumption of wildlife. London: Routledge.

Macbeth, J. (2005). Towards an ethics platform for tourism. Annals of Tourism Research, 32(4), 962-984.

McCool, S.F., Clark, R.N., Stankey, G.H., 2007. An Assessment of Frameworks Useful for Public Land Recreation Planning. General Technical Report PNWGTR-705 (March 2007).

Mehmetoglu, M. (2007). Typologising nature-based tourists by activity - Theoretical and practical implications. Tourism Management, 28, 651-660.

Meletis, Z. and Campbell, L. (2007). Call it consumption! Re-conceptualizing Ecotourism as Consumption and Consumptive. Geography Compass, 1/4, 850870.

Merchant, C. (1992). Radical Ecology. New York: Routledge.

Mill, R.C. and Morrison, A.M. (2009). The Tourism System. Kendall Hunt Pub Co.

Morito, B. (2000). Language, sustainable development, and Indigenous peoples: An ethical perspective. Ethics and the Environment, 5(1), 47-60.

Moulton, M.P. and Sanderson, J. (1999). Wildlife Issues in a Changing World. $2^{\text {nd }}$ Edition. Boca Raton, Florida: Lewis Publishers.

Newsome, D., Dowling, R. and Moore, S. (2002). Natural Area Tourism: Ecology, impacts and management. Clevedon: Channel View Publications.

Newsome, D., Dowling R. and Moore, S. (2005). Wildlife Tourism. Clevedon: Channel View Publications.

Parks Canada (2008). You Are in Black Bear Country. Parks Canada web site. www.pc.gc.ca/docs/v-g/ournoir-black-bear.index_E.asp

Paterson, B. (2006). Ethics for wildlife conservation: Overcoming the human-nature dualism. Bioscience, 56(2), 144-150.

Pepper, D. (1996). Modern Environmentalism: An introduction, London: Routledge.

Peterson, M.N. (2004). An approach for demonstrating the social legitimacy of hunting. Wildlife Society Bulletin, 32(2), 310-321.

Pitts, A. (2010) Wildlife Viewing and Ecotourism: Ethical, Scientific and ValueBased Considerations (Doctoral dissertation, The University of British Columbia, Canada). Retrieved from https://circle.ubc.ca/handle/2429/24649

Plumwood, V. (2003). Decolonizing relationships with nature. In W. M. Adams and M. Mulligan (Eds.), Decolonizing nature: Strategies for conservation in a postcolonial era (pp. 51-78). London: Earthscan.

Purser, R.E., Park, C. and Montuori, A. (1995). Limits to anthropocentrism: Toward an ecocentric organization paradigm? The Academy of Management Review, 20(4), 1053-1089. 
Regan, T. (1983). The case for animal rights. In J. Rachels (Ed.), The Right Thing to do: Basic reading in moral philosophy (pp. 211-225). New York: Random House.

Reynolds, P. and Braithwaite, D. (2001). Towards a conceptual framework for wildlife tourism. Tourism Management, 22(1), 31-42.

Schwartz, S. H. (1977). Normative influences on altruism. Advances in Experimental Social Psychology, 10, 221-279.

Seligman, C. (1989). Environmental ethics. Journal of Social Issues, 45, 169-184.

Shackley M. (1996). Wildlife Tourism. London: International Thomson Business Press.

Shrader-Frechette, K. (1981). Environmental Ethics. Pacific Grove, California: Boxwood Press.

Stenmark, M. (2002). The Relevance of Environmental Ethical Theories for Policy Making. Environmental Ethics, 24(2), 135-148.

Stern, P and Dietz, T. (1994). The value basis of environmental concerns. Journal of Social Issues, 50(3), 65-84.

Suchet, S. (1999). Situated engagement: A critique of wildlife management and postcolonial discourse (Doctoral dissertation, Macquarie University, Australia).

Thompson, S.C.G., and Barton, M.A. (1994). Ecocentric and anthropocentric attitudes toward the environment. Journal of Environmental Psychology, 14, 149-157.

Tully, J. (2001). An Ecological Ethics for the Present: Three Approaches to the Central Question. In B. Gleeson and N. Low (Eds.), Governing for the Environment: Global Problems, Ethics and Democracy, pp 147-164. Basingstoke: Palgrave.

Valentine, P.S., Weiler B. and Hall, C.M. (1992). Nature-based Tourism. In B. Weiler and C.M. Hall (Eds.), Special Interest Tourism, pp. 105-127. London: Belhaven Press.

WCED (World Commission for Environment and Development) (1987). Our Common Future. Oxford: Oxford University Press.

Weaver, D. (2001). Ecotourism. Milton, Qld: John Wiley and Sons Australia.

Weaver, D. (2005). Comprehensive and minimalist dimensions of ecotourism. Annals of Tourism Research, 32(2), 439-455.

Wight, P. (1996). North American ecotourists: Market profile and day trip characteristics. Journal of Travel Research, 24(4), 2-10.

Yasol-Naval, J. (2002). From Kapre to ecological consciousness: Indigenous beliefs and practices and the holistic perspective of environmental ethics. Kasarinlan: Phillipine Journal of Third World Studies, 17(1), 52-65.

Zografos, C. and Allcroft, D. (2007) The Environmental Values of Potential Ecotourists: A segmentation study. Journal of Sustainable Tourism, 15(1), 4466.

Figure 1: The Relationship Between Nature-Based Tourism, Ecotourism and Wildlife Tourism (Burns 2010).

Table 1: Seven Principles for an Ecocentric Approach to Wildlife Tourism.

Table 2: Seven strategies in the Fraser Island Dingo Management Strategy (FIDMS) (Corbett 2009). 